\title{
Method for experimentally determining N-A-S-(H) solubility
}

\author{
Trevor Williamson ${ }^{\mathrm{a}}$, Joonkyoung Han ${ }^{\mathrm{a}}$, Lynn Katz ${ }^{\mathrm{a}}$, Gaurav Sant ${ }^{\mathrm{b}}$, Maria C. G. Juenger ${ }^{{ }^{*}}$ \\ a The University of Texas at Austin Department of Civil, Architectural and Environmental Engineering; 301 E. Dean Keeton St. C1758, Austin, TX \\ 78712, USA \\ b University of California, Los Angeles Department of Civil and Environmental Engineering and Materials Science and Engineering; 420 \\ Westwood Plaza, Los Angeles, CA 90095, USA
}

Received: 07 June 2018 / Accepted: 09 February 2019 / Published online: 19 February 2019

(c) The Author(s) 2019. This article is published with open access and licensed under a Creative Commons Attribution 4.0 International License.

\begin{abstract}
Inorganic polymer binders, also sometimes called geopolymers or alkali-activated cements, can serve as an alternative to ordinary Portland cement (OPC) in concrete. The development of thermodynamic models to predict phase development and, ultimately, engineering properties, of inorganic polymer binders is an important step toward enabling their widespread use. However, such models require self-consistent solubility data of the primary phase in inorganic polymer binders, sodium aluminosilicate hydrate(s). To date, there is very little solubility information available for this phase. Here, a method is presented for synthesizing sodium aluminosilicate hydrate(s) of controlled composition and measuring solubility. This approach allows complete stoichiometric control over the (initial) solution composition to elucidate directly the development of N-A-S-(H) composition as it relates to a given solution composition. A review of previous literature related to the solubility of other cementitious materials is presented, and the need for thermodynamic data is discussed. Finally, a sample calculation is presented for determining the solubility product $\left(\mathrm{K}_{\mathrm{sp}}\right)$ of a laboratory synthesized sodium aluminosilicate hydrate.
\end{abstract}

Keywords: Geopolymers; Alkali-activated cement; Thermodynamic models; Solubility; Cement chemistry

\section{Introduction}

Inorganic polymer binders (IPBs) are a promising alternative to Portland cement and are made by activating an aluminosilicate powder, often coal fly ash, slags or metakaolin, with a highly alkaline activating solution, most commonly sodium hydroxide. Potassium hydroxide is a viable alternative to sodium hydroxide, and, regardless of which alkali cation is used, $\mathrm{OH}^{-}$plays the role of a dissolution catalyst, while the $\mathrm{Na}^{+}$or $\mathrm{K}^{+}$serve as valence compensating units in aluminum tetrahedra [1]. Sodium hydroxide generally provides greater release of silicates and aluminates from the aluminosilicate source, while potassium hydroxide tends to form larger silicate oligomers in solution at a given alkali to silicon ratio [1]. In the case of sodium hydroxide, which is the activator of focus in this study, the primary binding phase is sodium aluminosilicate hydrate (N-A-S-(H)). IPBs have comparable mechanical properties and, according to some studies, superior durability to Portland cement binders and may offer lower embodied energy and reduced $\mathrm{CO}_{2}$ emissions. A major technical challenge that must be overcome to promote the widespread use of these materials is that the primary aluminosilicate source material, fly ash, varies significantly from source to source. The successful implementation of these materials is dependent on our ability to quickly identify promising fly ash sources and then to predict and optimize mechanical properties and chemical stability for a given fly ash under a specific set of processing conditions.

The mechanical properties and durability of IPBs, like other cementitious materials, are highly dependent on the final phase assemblages and especially the relative portion of voids compared to solid phases [2]. The occurrence and extent of many durability issues are dependent on the chemical stability of the solid phases as well as the pore solution chemistry [3-6]. Thermodynamic modeling of calcium silicate hydrate (C-S-H) has successfully enabled the prediction of phase assemblages and porosity for Portland cement-based materials [7]. Recently, Myers et al. [8-11] expanded the data on C-S-H to include calcium aluminosilicate hydrate (C-A-S-H) as well. Experimental measurement of the solubility of a cementitious binding phase is a prerequisite for enabling thermodynamic calculations of phase assemblages. To date, there are few reliable solubility data for N-A-S- $(\mathrm{H})$, which prevents such assessments. An initial tabulation of N-A-S-(H) solubility products was presented by Gómez-Zamorano et al. [12], and the current study seeks to provide a consistent methodology to expand previous tabulations of N-A-S- $(\mathrm{H})$ solubility to a wider range of compositions and temperatures.

* Corresponding author: Maria Juenger, E-mail: mjuenger@mail.utexas.edu 
The goal of this paper is to present, in detail, a method for measuring N-A-S-(H) solubility data. This will enable other researchers to expand the thermodynamic data for N-A-S- $(\mathrm{H})$ using consistent methods, ultimately enabling the development of reliable thermodynamic models that can help promote the widespread use of IPB concrete. To achieve this end, first, the need for thermodynamic data to predict phase balances and engineering properties is discussed. Then, a review of previous solubility measurements and thermodynamic models for other cementitious materials is presented. Next, some general considerations are discussed, so that if the method presented here is modified, future researchers will better understand the impacts of modifications. Finally, a method for measuring the solubility of N-A-S- $(\mathrm{H})$ is presented. Many aspects of this method can be extended to solubility measurements of other cementitious phases as well.

\section{The need for N-A-S-(H) thermodynamic models}

The alkali-activation of aluminosilicates involves a complex series of reactions, with multiple steps that may occur simultaneously. At high $\mathrm{pH}$, monomeric speciation of both aluminum and silica is dominated by anionic species [13] as shown:

$$
\begin{aligned}
& \mathrm{SiO}_{2}+\mathrm{H}_{2} \mathrm{O}+\mathrm{OH}^{-} \rightarrow \mathrm{H}_{3} \mathrm{SiO}_{4}^{-} \\
& \mathrm{SiO}_{2}+2 \mathrm{OH}^{-} \rightarrow \mathrm{H}_{2} \mathrm{SiO}_{4}{ }^{2-} \\
& \mathrm{Al}_{2} \mathrm{O}_{3}+3 \mathrm{H}_{2} \mathrm{O}+2 \mathrm{OH}^{-} \rightarrow 2 \mathrm{Al}(\mathrm{OH})_{4}^{-}
\end{aligned}
$$

The monomers resulting from the alkali hydrolysis combine through a series of condensation reactions, forming a complex combination of soluble aluminate, silicate, and aluminosilicate oligomers, depending on the transient $\mathrm{Si} / \mathrm{Al}$ ratio in the solution.

Aluminum plays an important role in the polymerization process. Even though dissolved silicon tends to form soluble oligomers, sodium silicate solutions are stable at even relatively high concentrations [1]. In fact, it is the inherent low solubility of alkali-aluminosilicates that makes them viable candidates for a primary binder in a cementitious system, and adding aluminum to the solution is what allows the solid phases to form. It is well known that the total amount of aluminum available for reaction and the rate of release of aluminum can greatly affect the final phase balances, microstructure, and engineering properties (compressive strength, stiffness, tensile strength, durability) of IPBs [14].

In solutions with low Si/Al $(<1)$, condensation of silicate and aluminate monomers to form poly(sialate)-based gel is favored, while a higher Si/Al favors condensation of silicate monomers with other silicate monomers to form silicate oligomers, which then condense with aluminate monomers [15]. As dissolution proceeds, the solution quickly becomes supersaturated with respect to alkali-aluminosilicates that precipitate by forming large networks by further condensation. The resulting structure is referred to as a gel because of its bi-phasic nature, with the precipitated aluminosilicate and water released during condensation reactions forming the two phases.

The engineering properties of the precipitated gel are heavily dependent on its composition, atomic structure and microstructure, all of which are greatly affected by, but not easily correlated with: precursor properties, mixture proportions, and processing conditions (i.e. curing duration, temperature, relative humidity). For example, higher Si/Al ratios in solution lead to more $\mathrm{Si}-\mathrm{O}-\mathrm{Si}$ bonds, which are known to be stronger than Si-O-Al bonds. Compressive strength reaches a maximum at intermediate $\mathrm{Si} / \mathrm{Al}$, indicating that other factors outside of composition control the strength. For example, Duxson et al. [16] found that increasing Si/Al to 1.4 leads to a less porous microstructure, but increasing Si/Al beyond 1.65 decreases the lability of silicate species within the gel, ultimately reducing strength.

Correlating precursor properties to engineering properties is complicated by the fact that bulk $\mathrm{Si} / \mathrm{Al}$ is often not an accurate predictor of solution Si/Al, which ultimately governs the structure and composition of precipitating gel. This is especially true for fly ash systems due to the highly variable reactivity of aluminosilicate phases in fly ash. Dissolution of source material and precipitation of the binding phase occur simultaneously [1], and hardening is generally completed prior to complete dissolution of soluble phases, meaning that reactive aluminosilicate particles will remain in the hardening material. When correlating composition to strength, a further complicating factor is that these remaining source particles alter the final microstructure and therefore affect the compressive strength of the binder [16].

During the alkali dissolution of an aluminosilicate, solution $\mathrm{Si} / \mathrm{Al}$ evolves over time and is dependent on the kinetics and extent of silicate and aluminate dissolution at a given temperature, $\mathrm{pH}$, and the initial silica content in solution. Furthermore, the initial silica content not only affects Si/Al directly, but also indirectly by significantly enhancing aluminosilicate dissolution rates at concentrations above 200mM [17]. For activating solutions with little or no added silica, Si/Al at the time of mixing is low because aluminate dissolution is generally faster than silicate dissolution [18]. Initial Si/Al will thus be less than 1. For solutions with low Si/Al and high $\mathrm{pH}$, most aluminum in solution is present as $\mathrm{Al}(\mathrm{OH})_{4}^{-}$ [19]. Since the $\mathrm{Si} / \mathrm{Al}$ of precipitated gel is $>1$ because Al-O-Al bonds are unfavorable according to Loewenstein's rule, the $\mathrm{Si} / \mathrm{Al}$ in solution will decrease further as gel precipitates, and high concentrations of $\mathrm{Al}(\mathrm{OH})_{4}^{-}(\mathrm{aq})$ are expected in solution even after setting. This was, in fact, observed in metakaolin precursor IPBs studied by Duxson et al. [20].

Duxson et al. [20] also reported that for high silicate activating solution and metakaolin, Si/Al is high at initial mixing and decreases as aluminum is released preferentially. The $\mathrm{Si} / \mathrm{Al}$ is dependent on: (1) the initial amount of aluminum that is released prior to stoichiometric release and (2) the initial silicate concentration in the activator. For solutions where $\mathrm{Si} / \mathrm{Al}$ remains high, no $\mathrm{Al}(\mathrm{OH})_{4}{ }^{-}(\mathrm{aq})$ is expected to remain in solution after setting, and this was also observed by Duxson et al. [20]. Alternatively, Si/Al sometimes starts high (no 
$\left.\mathrm{Al}(\mathrm{OH})_{4}^{-}(\mathrm{aq})\right)$ and then decreases as solids with $\mathrm{Si} / \mathrm{Al}>1$ precipitate. If $\mathrm{Si} / \mathrm{Al}$ falls below about 2 , the remaining aluminosilicate species in solution will depolymerize, resulting in the presence of additional $\mathrm{Al}(\mathrm{OH})_{4}(\mathrm{aq})$ in solution after setting [20].

Further complicating the task of linking composition to engineering properties is the fact that initial speciation of the silicates in sodium silicate activating solution is highly complex and greatly impacts gel formation and structure. It is well known that properties of sodium silicate solutions, including viscosity and speciation of silicates, are highly dependent on the $\mathrm{Si} / \mathrm{Na}$ ratio of the solution $[21,22]$. As Si/Na increases, the number of $Q^{0}$ and $Q^{1}$ Si sites (monomeric and dimeric silicates) decreases rapidly [22]. This can cause a large change in gel microstructure [1], as aluminate anions react preferentially with silicate anions of lower connectivity [23]. As a result, not only is the $\mathrm{Si} / \mathrm{Al}$ ratio a key factor in geopolymer formation, but silicate speciation in the activating solution is equally or even more important.

Much attention has been paid to factors impacting dissolution of various silicate and aluminate-bearing phases from fly ash and to the effect of bulk Si/Al ratio of the system on engineering properties. The development of the "solid" gel from the liquid phase has been explored only briefly, however, and is critical in developing a full understanding of the factors influencing engineering properties [16]. Linking bulk Si/Al ratio directly to engineering properties is challenging because of the difficulties in deconvoluting the effects of the many variables discussed hitherto. The current study addresses that challenge by synthesizing monophasic gels from well-defined precursor solutions that contain solubilized silicates and aluminates. This approach (as opposed to studying fly ash directly) allows complete stoichiometric control over the (initial) solution composition to elucidate directly the development of N-A-S-(H) structure and composition as it relates to a given solution composition.

The work presented here focuses on understanding the composition and solubility relations of N-A-S- $(\mathrm{H})$ and thus emphasizes the relationship between the product phases and the initial solution chemistry. Successful modeling of the reaction from the precursor aluminosilicate powder and activating solution to the balance of product phases requires an understanding of how the oversaturated solution develops over time as a result of the dissolution of soluble phases from the source material. Many factors can affect the rate and extent of dissolution of the source material aluminosilicate phases, and these must be considered. The extent of dissolution, for example, decreases with increasing $\mathrm{Si} / \mathrm{Na}$ ratio (at constant $\mathrm{NaOH}$ concentration) due to the resulting drop in $\mathrm{pH}[1,20]$.

\section{Previous thermodynamic models and solubility measurements for cementitious phases}

While there are only a few studies quantifying the thermodynamics of $\mathrm{N}-\mathrm{A}-\mathrm{S}-(\mathrm{H})$, there have been several studies related to the solubility and thermodynamics of C-A-
S-H $[8-11,24]$. C-A-S-H is one of the primary binding phases existing in both Portland cement-based systems with aluminum-bearing supplementary cementitious materials and in high-calcium inorganic polymer binders. Thus, it represents an excellent starting point and system for comparison for similar studies of N-A-S-(H). C-A-S-H solubility has been measured experimentally by L'Hôpital et al. [24] and Myers et al. $[8,10]$. Both took a similar approach, dissolving amorphous $\mathrm{SiO}_{2}, \mathrm{CaO}$ (obtained by calcining $\mathrm{CaCO}_{3}$ ), and $\mathrm{CaO} \cdot \mathrm{Al}_{2} \mathrm{O}_{3}$ in Milli-Q water and measuring the composition of the precipitated $\mathrm{C}-\mathrm{A}-\mathrm{S}-\mathrm{H}$ phases as well as supernatant ion concentrations. Myers et al. [11] then used these data to develop a model describing the formation of various phases in the C-A-S-H systems.

García-Lodeiro et al. $[25,26]$ created synthetic N-A-S-(H) phases by combining sodium aluminate, sodium silicate, and sodium hydroxide, with the aim of studying the effects of adding calcium, specifically on the stability of C-A-S-H versus $\mathrm{N}-\mathrm{A}-\mathrm{S}-(\mathrm{H})$ in alkaline aluminosilicate systems containing both sodium and calcium. While they didn't specifically study the solubility of the synthesized phases, their work represents an important contribution towards the understanding of IPBs containing moderate to high levels of calcium.

Finally, Gómez-Zamorano et al. [12] tabulated N-A-S-(H) solubility products for $\mathrm{N}-\mathrm{A}-\mathrm{S}-(\mathrm{H})$ and $\mathrm{C}-\mathrm{A}-\mathrm{S}-\mathrm{H}$ that were prepared by double decomposition of calcium nitrate with sodium silicate. The current study seeks to provide a consistent method for expanding these tabulations to a wider range of temperatures and compositions.

\section{General considerations for method development}

There are some general considerations that were taken into account when developing the method presented in this study. Those considerations are discussed briefly in this section with the hope that it will help researchers understand the relative importance of various experimental practices for measuring solubility.

One of the most important considerations is ensuring that all work with solutions at high $\mathrm{pH}$ is conducted in a $\mathrm{CO}_{2}$-free environment (e.g., $\mathrm{N}_{2}$-filled glovebox, $\mathrm{CO}_{2}$ free/de-gassed water) to prevent $\mathrm{pH}$ reduction or precipitation of carbonate phases [27]. Addition of carbonate under controlled conditions (e.g. by maintaining a constant $\mathrm{P}_{\mathrm{CO} 2}$, or adding aqueous carbonate in a headspace free reactor) can be used to evaluate effects of carbonate under more realistic conditions. A second precaution for experiments that include dissolved $\mathrm{Na}, \mathrm{Si}$, or $\mathrm{Al}$, especially at high $\mathrm{pH}$, is to avoid use of glassware as silicate glasses dissolve readily at high $\mathrm{pH}$ $[21,28]$. In general, polyethylene or other polymers, such as Teflon, are more suitable. Preliminary experiments and control samples should be included to evaluate losses (or additions) of $\mathrm{Na}$, $\mathrm{Si}$, or Al when measuring N-A-S-(H) solubility, or the solubility of any cementitious phases.

Finally, the final measured ion concentrations that are used to calculate solubility are only as accurate as the dilution factors (since the concentrated solution needs to be diluted prior to 
analysis), so it is appropriate to measure dilution factors gravimetrically. This is especially important when measuring solubility at temperatures that vary significantly from ambient, as volumetric pipettes are designed to operate at near standard temperature. Temperature can also affect analytical balance measurements due to the air currents created by differences in sample temperature and the surrounding air. Temperature effects on the analytical balance did not need to be accounted for in this work because samples were diluted prior to weighing (and were therefore close to ambient temperature) before the mass was determined.

\section{Method for Measuring N-A-S-(H) Solubility $5.1 \quad \mathrm{~N}-\mathrm{A}-\mathrm{S}-(\mathrm{H})$ synthesis}

$\mathrm{N}-\mathrm{A}-\mathrm{S}-(\mathrm{H})$ samples were prepared by mixing stoichiometric proportions of de-gassed Milli-Q water (Merk Millipore) with $0.2 \mathrm{M} \mathrm{H}_{4} \mathrm{SiO}_{4}(0.2 \mathrm{M} \mathrm{Si})$ and $0.1 \mathrm{M} \mathrm{Na}_{2} \mathrm{Al}_{2} \mathrm{O}_{4}(0.2 \mathrm{M} \mathrm{Al})$ solutions in an $\mathrm{N}_{2}$-filled glove box to achieve a nominal pH of 14 (1 M $\mathrm{NaOH}$ ) and bulk molar Si/Al ratios between 1 and 2. N-A-S-(H) with $\mathrm{Si} / \mathrm{Al}$ of 1.5 is used as a case study here. This range of compositions was chosen as numerous studies in the literature have reported that optimum properties are achieved at molar Si/Al ratios in the range of 1 to $2[20,29-$ $31]$. In the present experiments, the sodium silicate activating solution had a Si/Na molar ratio of $0.1(2 \mathrm{M} \mathrm{NaOH}$ and $0.2 \mathrm{M}$ $\mathrm{H}_{4} \mathrm{SiO}_{4}$ ). This ratio was chosen to be low enough so that the dissolved silicates in solution would be monomers [22].

Generally, there are two choices for manipulating the bulk molar ratios in the synthesis of $\mathrm{N}-\mathrm{A}-\mathrm{S}-(\mathrm{H})$. The first option is to change the relative volumes of stock solutions that are mixed. This is the preferred method if the effects of bulk compositions, rather than the chemistry of the individual stock solutions, are of interest. The second option is to change relative concentrations of the stock solutions. For example, the Si concentration of the sodium silicate solution could be increased, resulting in a higher sodium silicate $\mathrm{Si} / \mathrm{Na}$ ratio and a higher bulk Si/Al ratio if the same relative volumes of each stock solution are mixed. This approach is preferred if is desired to study the effects of changing the chemistry of the individual stock solutions. As noted previously, the $\mathrm{Si} / \mathrm{Na}$ of the sodium silicate stock solution is an important variable and may impact the composition of the precipitated solid independent of the bulk $\mathrm{Si} / \mathrm{Al}$ ratio. In other words, two samples with the same bulk molar ratios may produce different $\mathrm{N}-\mathrm{A}-\mathrm{S}-(\mathrm{H})$ solids if there is a difference in $\mathrm{Si} / \mathrm{Na}$ ratios in the sodium silicate stock solution.

The synthesis conditions were based loosely on those employed by Myers et al. [10] and L'Hôpital et al. [24] in the synthesis of calcium aluminosilicates. A number of special precautions were taken to minimize contamination by $\mathrm{CO}_{2}$ and ensure accurate measurements of total and aqueous concentrations added to each reactor used to quantify solubility constants.

\subsubsection{Stock solution preparation}

Sodium silicate and sodium aluminate stock solutions were prepared in polypropylene (PP) volumetric flasks inside an $\mathrm{N}_{2}$ filled glovebox. All water was boiled (de-gassed) Milli-Q water. The sodium silicate stock solution was prepared by dissolving silicic acid (Sigma Aldrich, $20 \mu \mathrm{m}, 99.9 \%$, purified by refining) in $5 \mathrm{M}$ sodium hydroxide (Dilut-It, J.T. Baker) and diluting with de-gassed Milli-Q water to final concentrations of $2 \mathrm{M}$ sodium hydroxide and $0.2 \mathrm{M}$ silicic acid. Sodium aluminate solution was prepared at a concentration of $0.1 \mathrm{M}$ by dissolving sodium aluminate (Sigma Aldrich, technical grade, anhydrous; $\mathrm{Al}$ : $50-56 \%$ as $\mathrm{Al}_{2} \mathrm{O}_{3}, \mathrm{Na}: 40-45 \%$ as $\mathrm{Na}_{2} \mathrm{O}$ ) in de-gassed Milli-Q water. The sodium aluminate and silicic acid were weighed outside of the glovebox and transferred inside the glovebox prior to dissolution. Silicic acid is hygroscopic, so measuring the silicic acid by weight to achieve exactly $0.2 \mathrm{M} \mathrm{SiO}_{2}$ was not possible since the amount of water absorbed by the powder was not known. As such, a solution with $2 \mathrm{M} \mathrm{NaOH}$ and slightly higher than $0.2 \mathrm{M} \mathrm{Si}$ was prepared, and its concentration was measured using inductively coupled plasma optical emission spectrometry (ICP-OES, hereafter referred to as ICP). When the actual concentration of $\mathrm{SiO}_{2}$ was known, it could then be diluted to $0.2 \mathrm{M} \mathrm{Si}$ using $2 \mathrm{M} \mathrm{NaOH}$ (ensuring that the final $\mathrm{NaOH}$ concentration was $2 \mathrm{M}$ ). The final Si concentration was then once again measured and recorded, along with the final $\mathrm{Na}$ concentration. As with the silicic acid, the Al concentration of the sodium aluminate concentration was measured, and the solution was diluted to $0.1 \mathrm{M} \mathrm{Na}_{2} \mathrm{Al}_{2} \mathrm{O}_{4}$. The final $\mathrm{Al}$ and $\mathrm{Na}$ concentrations were then measured using ICP and recorded. For both the silicic acid and sodium silicate stock solutions, the 24 hour stir period was deemed to be sufficient because the concentrations of $\mathrm{Si}$ and $\mathrm{Al}$ in aliquots from the respective solutions passed through a $0.2 \mu \mathrm{m}$ syringe filter did not change between 24 and 48 hours, indicating that there were no particles larger than $0.2 \mu \mathrm{m}$ remaining in the solution after 24 hours. The final solutions were stored in high-density polyethylene (HDPE) bottles inside the glove box until ready for use (up to 3 months).

\subsubsection{Combining stock solutions to begin $\mathrm{N}-\mathrm{A}-\mathrm{S}-(\mathrm{H})$ synthesis}

The sodium silicate and sodium aluminate stock solutions were combined in $40 \mathrm{~mL}$ Oak Ridge high-speed PP copolymer centrifuge tubes with screw-on tops to achieve a bulk Si/Al molar ratio of 1.5. The volume of sodium silicate solution was $20 \mathrm{~mL}$ in all reactors, and the volume of sodium aluminate required to reach the desired bulk $\mathrm{Si} / \mathrm{Al}$ was calculated using the measured values of $\mathrm{Si}$ and $\mathrm{Al}$ concentrations. De-gassed Milli-Q water was then added to reach a total volume of 40 $\mathrm{mL}$. Concentrations of $\mathrm{NaOH}$ and $\mathrm{Si}$ in the sodium silicate stock solution were $2 \mathrm{M}$ and $0.2 \mathrm{M}$, respectively, so the bulk concentrations in each reactor were $1 \mathrm{M} \mathrm{NaOH}$ and $0.1 \mathrm{M} \mathrm{Si}$. The stock solutions were added to each reactor by volume, using a volumetric pipette, but the mass of each addition was recorded to more accurately determine bulk concentrations. 
The reactors for N-A-S-(H) synthesis were prepared inside the $\mathrm{N}_{2}$-filled glovebox. Twenty $\mathrm{mL}$ of the sodium silicate stock solution was added to one reactor vessel, the appropriate volume of the sodium aluminate stock solution was added to a separate vessel and an appropriate volume of de-gassed Milli-Q water was added to a third vessel. Quantities of all materials were determined gravimetrically. All three vessels were sealed tightly and removed from the glovebox. The masses of the following were recorded: (1) empty reaction vessel, (2) reaction vessel with sodium silicate solution, (3) sodium aluminate vessel with the sodium aluminate solution, (4) empty sodium aluminate vessel (measured after emptying the sodium aluminate solution into the reaction vessel), and (5) the reaction vessel with sodium silicate, sodium aluminate, and de-gassed Milli-Q water. The mass of sodium silicate solution was determined by subtracting (1) from (2); the mass of sodium aluminate solution was determined by subtracting (4) from (3), and the total solution mass was determined by subtracting (1) from (5). Knowing the mass of sodium silicate solution, sodium aluminate solution, and the overall mass of the sample, along with the $\mathrm{Si}$ and $\mathrm{Na}$ concentrations in the sodium silicate solution as well as the Al and $\mathrm{Na}$ concentrations in the sodium aluminate solution, the initial concentrations of $\mathrm{Si}, \mathrm{Al}$, and $\mathrm{Na}$ in each reactor could be accurately determined.

The three vessels were then placed in an oven at $50{ }^{\circ} \mathrm{C}$ (the reaction temperature chosen for this study) for two hours, long enough for the temperature of the solutions to equilibrate. Once the temperature of solutions in all three vessels reached the reaction temperature, they were placed in an insulated container and transported back to the glovebox. The reaction was initiated in the glove box by carefully pouring the sodium aluminate solution and degassed Milli- $Q$ water into the reaction vessel, which already contained the sodium silicate solution. Care was taken to make sure that all of the sodium aluminate solution and Milli$Q$ water made it into the reaction vessel. The reaction vessel was sealed tightly and removed from the glove box along with the now empty sodium aluminate vessel, and both were once again weighed to the nearest $\mathrm{mg}$. The seam of the reaction vessel was sealed with paraffin film to ensure that the reactor remained sealed throughout the experiment, and the vessel was returned to the temperature-controlled environment at the reaction temperature $\left(50^{\circ} \mathrm{C}\right)$ and placed on a rotisseriestyle tube rotator, rotating continuously at $8 \mathrm{rpm}$. Multiple reactors were prepared in this way simultaneously so that a fresh sample could be analyzed at each time point of the experiment. Since N-A-S-(H) equilibration times can be very long, extra samples were prepared beyond the samples that were expected to be analyzed at the multiple time points.

\subsubsection{Determining equilibration time}

The reactors were rotated continuously at $8 \mathrm{rpm}$, and supernatant $\mathrm{Si}$ and $\mathrm{Al}$ concentrations were monitored over time using ICP-OES to determine how long it would take the precipitated N-A-S- $(\mathrm{H})$ to equilibrate. For the first two or three supernatant $\mathrm{Si}$ and $\mathrm{Al}$ measurements, supernatants were taken from the same reaction vessel, since determining exact
Si and Al concentrations over time was not the primary aim of this study. All supernatant samples used to determine equilibrium products were taken from previously unopened reaction vessels. Since there is little information available about equilibration times for N-A-S-(H), the selection of initial time points was based on the equilibration times for C-A-S-H reported by Myers et al. [10]. C-A-S-H equilibration times were 1 year at $7{ }^{\circ} \mathrm{C}, 182$ days at $20^{\circ} \mathrm{C}$, and 56 days at $50{ }^{\circ} \mathrm{C}$ and $80{ }^{\circ} \mathrm{C}$ and were chosen based on changes $(<25 \%)$ in dissolved $\mathrm{Si}, \mathrm{Al}$, and $\mathrm{Ca}^{2+}$ concentrations. In the study on $\mathrm{N}-\mathrm{A}$ $\mathrm{S}-(\mathrm{H})$ presented here, several time points $(3,7,10,14,29$, and 56 days at $50^{\circ} \mathrm{C}$ ) were chosen between 0 days and anticipated equilibration times based on C-A-S-H. Equilibrium was defined as the time point when there was less than a $10 \%$ change in $\mathrm{Si}$ and $\mathrm{Al}$ concentrations between the equilibrium time point and the prior time point [32], which was 56 days in this study. Since the focus of this study was on the equilibrium conditions, after the initial path and time to equilibrium was established, replicate samples were generally only analyzed at the equilibrium time.

\subsubsection{Sampling methodology}

As indicated earlier, once the equilibration time was determined, samples were prepared as described above and placed on the rotators in temperature controlled environments for the appropriate number of days ( 56 days for this study). The reactors were then quickly transported from the rotator in the temperature-controlled environment to the $\mathrm{N}_{2}$-filled glovebox in an insulated container to keep them as near to the reaction temperature as possible. Once inside the glovebox, the reactors were immediately placed in a dry bath incubator that was already equilibrated to the reaction temperature of the current experiment to ensure constant temperature prior to sampling.

After the reactors were in the dry bath incubator, the cap of one of the reactors was removed, and a $6 \mathrm{~mL}$ syringe was used to draw up about $1 \mathrm{~mL}$ of supernatant from the top of the reactor. Then, a $0.2 \mu \mathrm{m}$ polyvinylidene fluoride syringe filter was placed on the syringe, and the supernatant was transferred into a separate acid-washed $15 \mathrm{~mL}$ PP centrifuge tube. Since supernatant dissolved $\mathrm{Na}$ concentrations were on the order of $1 \mathrm{M}$ compared to dissolved $\mathrm{Si}$ and $\mathrm{Al}$ concentrations, which were generally less than $0.1 \mathrm{M}$, different dilution factors had to be used to bring the concentrations within the linear range of the ICP. Aliquots were diluted approximately $1000 \times$ for measurement of $\mathrm{Na}$ concentrations, and approximately $100 \times$ for measurement of $\mathrm{Si}$ and $\mathrm{Al}$ concentrations. To this end, $100 \mu \mathrm{L}$ of filtered supernatant was pipetted into the $125 \mathrm{~mL}$ dilution vessel (which already contained $99 \mathrm{~g} 3 \%$ nitric acid solution prepared with Milli-Q water), and another $100 \mu \mathrm{L}$ of filtered supernatant was pipetted into the $15 \mathrm{~mL}$ dilution vessel (which already contained $9.9 \mathrm{~mL} 3 \%$ nitric acid). Both dilution vessels were immediately inverted a minimum of 25 times, and the diluted samples were removed from the glove box and once again weighed to the nearest $0.1 \mathrm{mg}$, then stored up to 3 months prior to ICP analysis. 


\subsection{Measuring $\mathrm{Na}, \mathrm{Si}$, and $\mathrm{Al}$ concentrations with ICP}

Measurement of $\mathrm{Na}, \mathrm{Si}$ and $\mathrm{Al}$ concentrations generally followed standard procedures [33,34]. However, due to the range in ionic strength, variable temperature, and high $\mathrm{pH}$ of the samples, a number of special precautions were taken to ensure analytical quality control. At each of the time points described in section 5.1.3, aliquots of supernatant were prepared for ICP to measure $\mathrm{Si}, \mathrm{Al}$, and $\mathrm{Na}$ as described in 5.1.4.

Supernatant $\mathrm{Na}, \mathrm{Si}$, and $\mathrm{Al}$ concentrations were determined using a Varian 10-ES ICP-OES with a SPS 3 autosampler following EPA Method 200.7 [34] and ICP Expert II software (v 1.1). Multiple wavelengths were evaluated for both standards and samples; for $\mathrm{Na}$ intensities of two wavelengths were measured ( 568.821 and $589.592 \mathrm{~nm}$ ), while for Si and Al the intensities of three wavelengths were measured for each (185.005, 250.690, and $251.611 \mathrm{~nm}$ for Si; 237.312, 394.401, and $396.152 \mathrm{~nm}$ for Al). Calibration curves prepared at each wavelength for these elements provided consistent results.

Two sets of standards were used for the measurement of dissolved $\mathrm{Si}, \mathrm{Al}$, and $\mathrm{Na}$ in the filtered, diluted, and acidified supernatants. The most important consideration when preparing ICP standards is that the matrix of the standard set closely matches the matrix of the sample being analyzed. For the samples prepared to measure Na concentrations, which had been diluted $1000 \times$, Na concentrations were on the order of $1 \mathrm{mM}$, and Si and Al concentrations were less than $0.1 \mathrm{mM}$. Since the background ion ( $\mathrm{Si}$ and $\mathrm{Al}$ ) concentrations were so low in the Na samples, it was assumed that they did not need to be included in the standard matrix. This assumption was tested and found to be valid using the method of standard additions [35], a method commonly used to assess the extent of matrix effects. For the samples prepared to measure $\mathrm{Si}$ and $\mathrm{Al}$, on the other hand, $\mathrm{Na}$ concentrations were approximately $10 \mathrm{mM}$, so Na had to be added to the standard (in the form of $\mathrm{NaOH}$ ). For these samples, a combined standard was prepared to measure Si and Al. Again, the method of standard additions was used to make sure the matrix effects were accounted for properly and to ensure that the Si and Al were not interfering with each other. Both sets of standards were prepared with a $3 \%$ nitric acid matrix to match the diluted, acidified samples.

\subsection{Solid composition measurements}

In addition to supernatant $\mathrm{Na}, \mathrm{Si}$, and $\mathrm{Al}$ concentrations, the relative elemental compositions of the precipitated N-A-S- $(\mathrm{H})$ phases were required in order to calculate solubility products. To determine the N-A-S-(H) Si/Al compositions, a mass balance approach was taken. Changes in the supernatant $\mathrm{Si}$ and $\mathrm{Al}$ concentrations between the initial concentrations and the equilibrium concentrations were determined by subtraction. The difference in concentrations was the relative amount of that element that was determined to have precipitated out of solution. For example, if the bulk Si/Al concentration was 2 , with initial supernatant $\mathrm{Si}$ concentration of $200 \mathrm{mM}$ and initial $\mathrm{Al}$ concentration of $100 \mathrm{mM}$, and equilibrium supernatant concentrations were measured as 50 $\mathrm{mM}$ and $20 \mathrm{mM}$ for Si and Al, respectively, then $150 \mathrm{mmol}$ of $\mathrm{Si}$ would have been removed from solution per liter of solution, while $80 \mathrm{mmol}$ of Al would have been consumed. The elemental molar ratio in the solid for this example would then be calculated as 150 divided by 80 , or 1.88 .

To validate the mass balance approach for determining the relative $\mathrm{Si}$ and $\mathrm{Al}$ concentrations in the N-A-S-(H) phases, some of the solids were centrifuged, freeze-dried, and digested using a mixture of hydrofluoric and hydrochloric acids and analyzed by ICP to determine the solid composition. The solids were triple-rinsed with Milli- $Q$ water by dispersing them in the water, centrifuging at $3000 \mathrm{~g}$ for 10 minutes, and decanting. It was assumed that the re-dissolution of solids to the water is negligible. The solids were then frozen with liquid $\mathrm{N}_{2}$ for 5 minutes, freeze dried at $-50{ }^{\circ} \mathrm{C}$ and 5 Pa for 48 hours using a Labconco Freezone Bulk Tray Dryer and stored at -20 ${ }^{\circ} \mathrm{C}$ under $\mathrm{N}_{2}$ until further analysis.

The solids were digested following a detailed protocol developed by Inorganic Ventures specifically for the compositional analysis of zeolites. The protocol uses two premixed, proprietary solutions: (1) Inorganic Ventures UA-1, comprised of proprietary proportions hydrofluoric and hydrochloric acids to digest the solids, and (2) Inorganic Ventures UNS-1, comprised of proprietary proportions of triethanolamine and triethylenetetramine to buffer the acids used for digestion. To perform the digestion, 80 to $100 \mathrm{mg}$ of freeze-dried solids were weighed to the nearest $0.1 \mathrm{mg}$ and added to a polyethylene bottle. Ten drops of deionized water were then added to the solids, and the bottle was swirled to hydrate the surface of the solids. Next, $10 \mathrm{~mL}$ of UA-1 and 0.5 $\mathrm{mL}$ of concentrated nitric acid (trace metal grade, Fisher) were added, and the vessel was capped and shaken for 3 minutes (at this point, the solid appeared completely dissolved to the naked eye). The resulting solution was neutralized by adding $50 \mathrm{~mL}$ of UNS-1, and the final solution weight was adjusted to $500 \mathrm{~g}$ using deionized water. Finally, the solution was analyzed using ICP in the same way that supernatant concentrations were measured (described previously).

Unfortunately, relative Na concentrations in the solids could not be determined by mass balance or by hydrofluoric acid digestion with ICP. They could not be determined by mass balance because the relative changes in supernatant $\mathrm{Na}$ concentrations were too small compared to the initial $\mathrm{Na}$ concentrations, since initial $\mathrm{Na}$ concentrations were on the order of $1 \mathrm{M}$. The N-A-S-(H) relative Na concentrations could not be determined by ICP analysis, either, because there were matrix issues with the hydrofluoric acid and buffers that prevented linear calibration curves from being established, despite substantial effort. Instead, the molar fractions of $\mathrm{Na}_{2} \mathrm{O}$ were assumed to be equal to the molar fractions of $\mathrm{Al}_{2} \mathrm{O}_{3}$ for each sample (i.e. $\mathrm{Na}_{2} \mathrm{O} / \mathrm{Al}_{2} \mathrm{O}_{3}=1$ ) based on the assumption that sodium is present as a charge balancing cation to alumina tetrahedra, which carry a -1 charge [1].

The water contents of N-A-S-(H) phases were determined by thermogravimetric analysis (TGA). The solids were vacuumfiltered using nylon filter membranes with a pore size of 0.45 
$\mu \mathrm{m}$ and a diameter of $47 \mathrm{~mm}$. While on the filter, with the vacuum running, the solids were triple washed with DI water, and then allowed to sit, with the vacuum running, for 5 minutes to remove excess water. They were then stored, for a maximum of 7 days, under $\mathrm{N}_{2}$ at $4{ }^{\circ} \mathrm{C}$ until undergoing TGA. Thermogravimetric data were collected using a Mettler Thermogravimetric Analyzer, Model TGA/DSC 1 with a sensitivity of $2 \mu \mathrm{g}$. The vacuum-filtered samples were equilibrated at $40^{\circ} \mathrm{C}$ for one hour and then heated from $40^{\circ} \mathrm{C}$ to $600{ }^{\circ} \mathrm{C}$ under $\mathrm{N}_{2}$ at a flow rate of $20 \mathrm{ml} /$ minute with a heating rate of $20{ }^{\circ} \mathrm{C} /$ minute in pure aluminum oxide crucibles. The $40{ }^{\circ} \mathrm{C}$ equilibration period was to allow for the evaporation of excess water so that the water content contained in the solid phases could be accurately quantified.

\subsection{Solubility product calculations}

To determine solubility products for synthesized N-A-S-(H) of various starting solution compositions and various reaction equilibration temperatures, an ion activity product (IAP) was calculated for each of the equilibrated N-A-S-(H) phases.

The dissolution reaction assumed for calculating solubility products is shown in Eq. (4), according to a common convention [36]:

$\mathrm{NaAlSi}_{x} \mathrm{O}_{(2 x+2)} \cdot\left(\mathrm{H}_{2} \mathrm{O}\right)_{y(\mathrm{~S})}+(2 x-y-2) \mathrm{H}_{2} \mathrm{O}_{(l)}+$ $4 H_{(a q)}^{+} \leftrightarrow \mathrm{Na}_{(a q)}^{+}+\mathrm{Al}_{(a q)}^{3+}+x \mathrm{H}_{4} \mathrm{SiO}_{4(a q)}^{o}$

where $x$ is the Si/Al molar ratio of the solids and $y$ is the stoichiometric coefficient of $\mathrm{H}_{2} \mathrm{O}$ in the hydrated solids. Here, $\mathrm{Al}^{3+}{ }_{\text {(aq) }}$ refers to the specific species, where previously, $\mathrm{Al}$ referred to the total aluminum. Following the reaction in Eq. (4), equilibrium solubility products were calculated with Eq. (5):

$K_{s p}=\left\{\mathrm{Na}_{(a q)}^{+}\right\} \cdot\left\{\mathrm{Al}_{a q}^{3+}\right\} \cdot\left\{\mathrm{H}_{4} \mathrm{SiO}_{4(a q)}^{\mathrm{o}}\right\}^{x} \cdot\left\{\mathrm{H}_{(a q)}^{+}\right\}^{-4}$.

$\left\{\mathrm{H}_{2} \mathrm{O}_{(l)}\right\}^{(y-2 x+2)}$

Activities of $\mathrm{Na}^{+}{ }_{(\mathrm{aq})}, \quad \mathrm{Al}^{3+}{ }_{(\mathrm{aq}),} \mathrm{H}_{4} \mathrm{SiO}_{4}{ }_{(\mathrm{aq})}{ }$, and $\mathrm{H}_{2} \mathrm{O}_{(\mathrm{l})}$ were determined with PHREEQC using the measured supernatant concentrations of $\mathrm{Na}, \mathrm{Si}$, and $\mathrm{Al}$ with the $\mathrm{pH}$ calculated from charge balance. An attempt was made to measure $\mathrm{pH}$ experimentally, but between the combination of very high $\mathrm{pH}$ (close to 14) and very high sodium concentrations (on the order of $1 \mathrm{M}$ ), reliable $\mathrm{pH}$ values could not be measured because of the measurement errors that can occur under these conditions. In fact, the variation in $\mathrm{pH}$ values measured for a given sample was greater than the difference in $\mathrm{pH}$ between samples.

The Truesdell-Jones version of the extended Debye-Hückel equation was used within PHREEQC with the Lawrence Livermore National Laboratory database to determine activity coefficients of each species, shown in Eq. (6):

$\log \gamma_{i}=\frac{-A z_{i}^{2} \sqrt{I}}{1+B \alpha_{i} \sqrt{I}}+b I$

where $\gamma_{i}$ is the activity coefficient of ion " $i$ ", $A$ and $B$ are DebyeHückel parameters based on the dielectric constant of water and the temperature, $z_{i}$ is the ion valance, $\alpha_{i}$ is a parameter accounting from the ionic radius, $b$ is an empirical parameter, and $/$ is the ionic strength of the solution. Robinson and Stokes
[37] found that the Truesdell-Jones extension of the DebyeHückel equation predicts activity coefficients consistent with experimental data for ionic strengths up to at least $1 \mathrm{M}$. In the study presented here, ionic strengths were very near $1 \mathrm{M}$ for all samples (see Appendix A) and fall at the upper limit of Truesdell-Jones applicability. The Pitzer model offers more flexibility to determine activity coefficients of solutions with high ionic strength, however that flexibility comes with increased parameterization complexity [38].

\section{Sample Calculation}

In this section, sample calculations for a single batch reactor are presented for the following: (1) initial bulk reactor $\mathrm{Na}, \mathrm{Si}$, and $\mathrm{Al}$ concentrations (from $\mathrm{Na}, \mathrm{Si}$, and $\mathrm{Al}$ concentrations in stock solutions, masses of stock solutions, and total solution mass), (2) equilibrium supernatant concentrations (from ICP data), (3) equilibrium solid compositions (from initial bulk reactor concentrations and equilibrium supernatant concentrations), (4) equilibrium supernatant activities (from equilibrium supernatant compositions, using PHREEQC), and (5) solubility products (from equilibrium supernatant activities and solid compositions). The batch reactor experiment used for the sample calculations was reacted at $50{ }^{\circ} \mathrm{C}$ for 56 days with a target bulk Si/Al ratio of 1.5 .

\subsection{Initial bulk reactor concentration calculation}

Initial bulk reactor $\mathrm{Na}, \mathrm{Si}$, and $\mathrm{Al}$ concentrations were calculated from the concentrations of $\mathrm{Na}, \mathrm{Si}$, and $\mathrm{Al}$ in the stock solutions and the relative amounts of stock solutions added to the reactor. For the reactor reacted at $50{ }^{\circ} \mathrm{C}$ for 56 days with a target bulk $\mathrm{Si} / \mathrm{Al}$ solution of 1.5 , the sodium silicate stock solution contained $178 \mathrm{mmol} / \mathrm{kg} \mathrm{Si}$ and $1840 \mathrm{mmol} / \mathrm{kg}$ $\mathrm{Na}$, and the sodium aluminate stock solution contained 229 $\mathrm{mmol} / \mathrm{kg} \mathrm{Al}$ and $275 \mathrm{mmol} / \mathrm{kg} \mathrm{Na}$. The stock solution concentrations were measured using ICP-OES (for sample ICP calculations, see section 6.2).

To determine the mass of stock solution added to each reactor, the mass of each of the following was measured: (1) empty reaction vessel, (2) reaction vessel with sodium silicate solution, (3) sodium aluminate vessel with the sodium aluminate solution, (4) empty sodium aluminate vessel (measured after emptying the sodium aluminate solution into the reaction vessel), and (5) the reaction vessel with sodium silicate, sodium aluminate, and de-gassed Milli-Q water. Those measured masses for the sample reactor are shown in Table 1.

Table 1. Mass of stock solutions and vessels used to synthesize N-A-S-(H).

\begin{tabular}{ll}
\hline Item & Mass (g) \\
\hline 1. Empty Reaction Vessel & 16.32 \\
2. Reaction Vessel (RV) + Sodium Silicate (SS) & 38.12 \\
3. Sodium Aluminate (SA) + SA Vessel & 17.89 \\
4. Empty SA Vessel & 6.53
\end{tabular}


5. $R V+S A+S S+M P W$

58.25

The mass of sodium silicate solution, sodium aluminate solution, and total solution mass were then determined by subtraction and are shown in Table 2.

Table 2. Mass of stock solutions used to synthesize N-A-S-(H).

\begin{tabular}{ll}
\hline Solution & Mass (g) \\
\hline Sodium Silicate Stock (Item 2 - 1) & 21.80 \\
Sodium Aluminate Stock (Item 3 - 4) & 11.36 \\
Total (includes MPW) (Item 5 - 1) & 41.93 \\
\hline
\end{tabular}

Knowing the mass as well as the $\mathrm{Na}$, $\mathrm{Si}$, and $\mathrm{Al}$ concentrations of the stock solutions added to the reactor, the bulk concentrations of $\mathrm{Na}, \mathrm{Si}$, and $\mathrm{Al}$ in the reactor were determined using Eq. (7):

$C_{\text {bulk }}=\frac{M_{\text {stock }} \times C_{\text {stock }}}{M_{\text {total }}}$

where $C_{\text {bulk }}$ is the bulk concentration in the reactor, Mstock and $C_{\text {stock }}$ are the masses and concentrations of the respective stock solutions, and Mtotal is the total mass of solution in the reactor. The bulk Na concentration is taken as the sum of the contributions to bulk $\mathrm{Na}$ concentrations from the sodium silicate and sodium aluminate stock solutions. The bulk concentrations of $\mathrm{Na}, \mathrm{Si}$, and $\mathrm{Al}$ in the sample reactor are shown in Table 3.

Table 3. Bulk $\mathrm{Na}, \mathrm{Si}$, and $\mathrm{Al}$ concentrations in sample reactor.

\begin{tabular}{ll}
\hline Species & Conc., $\mathrm{mmol} / \mathrm{kg}$ \\
\hline $\mathrm{Na}$ & 1029 \\
$\mathrm{Si}$ & 92.35 \\
$\mathrm{Al}$ & 61.06 \\
\hline
\end{tabular}

The bulk Si/Al ratio was then simply determined by dividing the measured bulk Si concentration by the measured bulk Al concentration. For this sample, the measured bulk Si/Al ratio was 1.51 (compared to the target bulk Si/Al of 1.5).

\subsection{Equilibrium solid composition calculation}

The relative amounts of Si and $\mathrm{Al}$ in the precipitated N-A-S- $(\mathrm{H})$ were determined using a mass balance approach. Changes in the supernatant $\mathrm{Si}$ and $\mathrm{Al}$ concentrations between the initial concentrations and the equilibrium concentrations were determined by subtraction. The difference in concentrations was the relative amount of that element that was determined to have precipitated out of solution.

For the sample reactor presented here, the initial bulk Si and Al concentrations were $92.35 \mathrm{mmol} / \mathrm{kg}$ and $61.06 \mathrm{mmol} / \mathrm{kg}$, respectively, while the supernatant $\mathrm{Si}$ and $\mathrm{Al}$ concentrations were $34.10 \mathrm{mmol} / \mathrm{kg}$ and $2.38 \mathrm{mmol} / \mathrm{kg}$, respectively. By subtraction, for every $1 \mathrm{~kg}$ solution, $58.25 \mathrm{mmol} \mathrm{Si}$ and 58.68 $\mathrm{mol} \mathrm{Al}$ would have been incorporated in the solid, giving a solid Si/Al molar ratio of 0.99 . It should be noted that the Si/Al ratio of the solid is lower than the starting solution; this relationship will be discussed further in a subsequent publication [32].

The relative water content of the equilibrated N-A-S-(H) solid was also required to determine solubility products. The water content was calculated from the mass loss measured using TGA. For the solid collected from the sample reactor presented here, the mass loss was measured to be $21.6 \%$ (i.e. $21.6 \%$ of the solid mass was attributed to water). From the measured water loss and the known molar $\mathrm{Si} / \mathrm{Al}$ and $\mathrm{Na} / \mathrm{Al}$ ratios, the molar ratio $\mathrm{H}_{2} \mathrm{O} / \mathrm{Al}$ was determined using Equation (8):

$$
\frac{\mathrm{H}_{2} \mathrm{O}}{\mathrm{Al}}=\frac{T W \times\left[\mathrm{Si} \times M W_{\mathrm{SiO}_{2}}+\frac{\mathrm{Al}}{2} \times M W_{\mathrm{Al}_{2} \mathrm{O}_{3}}+\frac{\mathrm{Na}}{2} \times M W_{N a_{2} \mathrm{O}}\right]}{(100-T W) \times M W_{\mathrm{H}_{2}} \mathrm{O}}
$$

where TW is the mass loss measured by TGA (21.6\%), Si, Al, and $\mathrm{Na}$ are the molar ratios Si/Al (0.99), $\mathrm{Al} / \mathrm{Al}$ (1.00), and $\mathrm{Na} / \mathrm{Al}$ (1.00), and $M W_{\text {SiO2 }}, M W_{\mathrm{Al} 2 \mathrm{O} 3}, M W_{\mathrm{Na2O}}$, and $M W_{\mathrm{H} 2 \mathrm{O}}$ are the molecular weights of $\mathrm{SiO}_{2}, \mathrm{Al}_{2} \mathrm{O}_{3}, \mathrm{Na}_{2} \mathrm{O}$, and $\mathrm{H}_{2} \mathrm{O}$, respectively. The molar ratio $\mathrm{H}_{2} \mathrm{O} / \mathrm{Al}$ for the solid in the sample reactor was calculated to be 2.16. The solid composition for this sample was thus determined to be $\mathrm{NaAlSi}_{0.99} \mathrm{O}_{3.98} \cdot\left(\mathrm{H}_{2} \mathrm{O}\right)_{2.16}$.

\subsection{Equilibrium supernatant activity calculation}

Activities of $\mathrm{Na}^{+}{ }_{(\mathrm{aq})}, \mathrm{Al}^{3+}{ }_{(\mathrm{aq})}, \mathrm{H}_{4} \mathrm{SiO}_{4}{ }^{\circ}{ }_{(\mathrm{aq})}, \mathrm{H}^{+}{ }_{(\mathrm{aq})}$, and $\mathrm{H}_{2} \mathrm{O}_{(\mathrm{l})}$ and the $\mathrm{pH}$ were determined with PHREEQC using the measured supernatant concentrations of $\mathrm{Si}, \mathrm{Al}$, and $\mathrm{Na}$ with the $\mathrm{pH}$ calculated from charge balance (with a starting $\mathrm{pH}$ of 13 as an input for PHREEQC to iterate from). The full PHREEQC input and output for the sample reactor activity calculations are shown in Appendix A. The PHREEQC outputs that are required for the direct calculation of the solubility product are summarized in Table 4. Solubility products were calculated in units of $\mathrm{mol} / \mathrm{kg}$ soln, so the output activities were converted accordingly (also shown in Table 4).

Table 4. Supernatant activities of species needed to calculate N-A-S(H) solubility product for sample reactor.

\begin{tabular}{lll}
\hline Species & Activity (molal) & Activity (mol/kg soln) \\
\hline $\mathrm{Na}$ & $6.09 \times 10^{-1}$ & $5.95 \times 10^{-1}$ \\
$\mathrm{Al}$ & $2.43 \times 10^{-35}$ & $2.38 \times 10^{-35}$ \\
$\mathrm{H}_{4} \mathrm{SiO}_{4}{ }^{\circ}$ & $5.22 \times 10^{-7}$ & $5.10 \times 10^{-7}$ \\
$\mathrm{H}^{+}$ & $8.68 \times 10^{-14}$ & $8.48 \times 10^{-14}$ \\
$\mathrm{H}_{2} \mathrm{O}$ & $9.67 \times 10^{-1}$ & $9.44 \times 10^{-1}$ \\
\hline
\end{tabular}

\subsection{Solubility product calculation}

Solubility products were calculated with Eq. 5 . For the sample reactor presented here, substituting the values presented in sections 6.1-6.3, the solubility product was determined to be $1.28 \times 10^{11}$. The solubility product determined will be compared against literature values in a forthcoming publication [32]. 


\section{Conclusions}

A method for measuring the solubility of N-A-S- $(\mathrm{H})$ phases experimentally has been presented in detail. Additionally, the need for solubility data and thermodynamic models for N-A$\mathrm{S}-(\mathrm{H})$ was discussed. Previous literature relating to the solubility and thermodynamic models of C-S-H and C-A-S-H was also reviewed, and some general considerations for developing the method were discussed. The calculations required to determine solubility products from the experimental data were described, and a sample calculation was presented.

There is some room for improvement in the method itself, and the hope is that future research will use this method as a starting point, expanding and improving upon it continually. Specifically, the method for determination of solid N-A-S-(H) composition can be improved upon, especially with regards to sodium concentration. Ideally, the relative sodium composition in N-A-S-(H) phases could be determined by hydrofluoric acid digestion with ICP analysis. A substantial effort was placed on achieving reliable sodium contents in this way in the study presented here, but the complex matrix that resulted from the digestion itself proved to be difficult to account for.

\section{Acknowledgements}

The authors thank Philip Bennett, Aditya Kumar, and Howard Dobbs for their assistance in developing the experimental methods presented in this study, as well as for reviewing the manuscript. The authors also thank Michelle Lacks, Kevin Folliard, Victoria Ibarra, Phil Tomlin, Michael Williams, and Lamont Prosser for their support. Federal Highway Administration's Exploratory Advanced Research Program provided financial support for the study presented in this paper through Project DTFH61-13-H-00011, for which the authors are also grateful.

\section{Appendix A}

The PHREEQC input and output files for the sample calculation presented in section 6 are shown here.

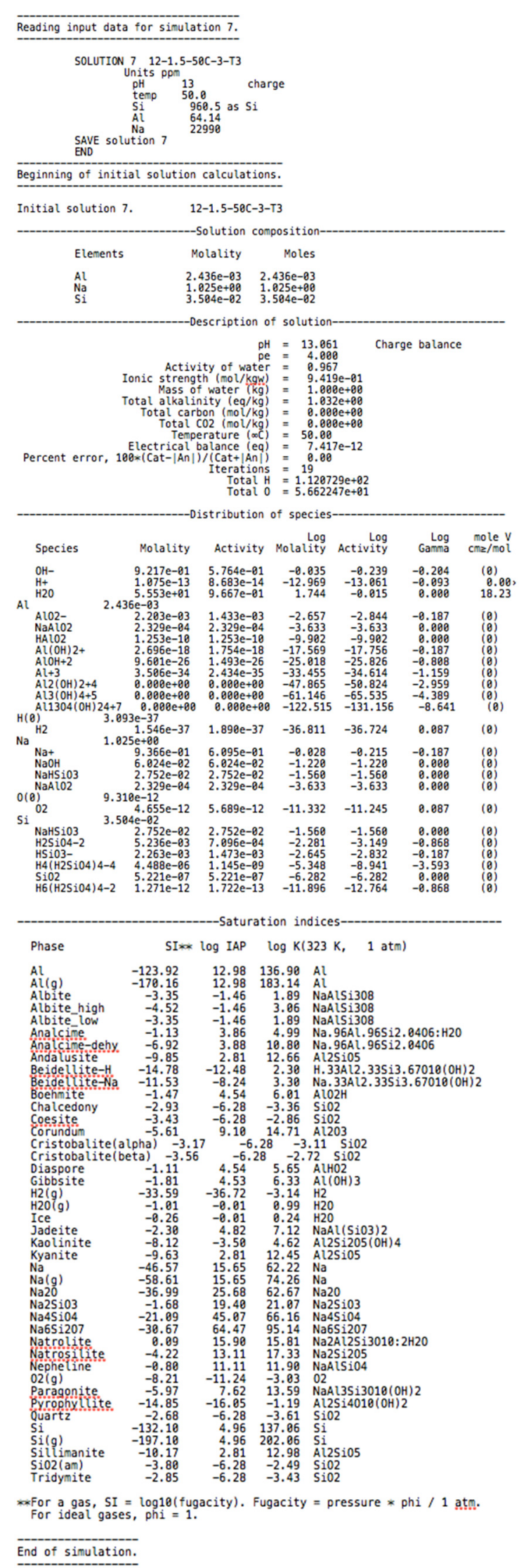




\section{References}

[1] P. Duxson, A. Fernández-Jiménez, J.L. Provis, G.C. Lukey, A. Palomo, J.S.J. Deventer, Geopolymer technology: the current state of the art, J Mater Sci (2006) 42: 2917-2933. https://doi.org/10.1007/s10853-006-0637-z

[2] D.A. Kulik, M. Kersten, Aqueous solubility diagrams for cementitious waste stabilization systems. 4. A carbonation model for Zn-Doped calcium silicate hydrate by Gibbs energy minimization, Environ Sci Technol (2002) 36: 2926-2931.

https://doi.org/10.1021/es010250v

[3] R.S. Barneyback, S. Diamond, Expression and analysis of pore fluids from hardened cement pastes and mortars, Cem Concr Res (1981) 11: 279-285. https://doi.org/10.1016/0008-8846(81)90069-7

[4] L.. Struble, The Influence of Cement Pore Solution on Alkali Silica Reaction, 1987.

[5] T. Williamson, M.C.G. Juenger, The role of activating solution concentration on alkali-silica reaction in alkali-activated fly ash concrete, Cem Concr Res (2016) 83: 124-130.

https://doi.org/10.1016/j.cemconres.2016.02.008

[6] F. Rajabipour, E. Giannini, C. Dunant, J.H. Ideker, M.D. a. Thomas, Alkali-silica reaction: Current understanding of the reaction mechanisms and the knowledge gaps, Cem Concr Res (2015) 76: 130-146. https://doi.org/10.1016/j.cemconres.2015.05.024

[7] B. Lothenbach, T. Matschei, G. Möschner, F.P. Glasser, Thermodynamic modelling of the effect of temperature on the hydration and porosity of Portland cement, Cem Concr Res (2008) 38: 1-18. https://doi.org/10.1016/i.cemconres.2007.08.017

[8] R.J. Myers, E. L'Hopital, J.L. Provis, B. Lothenbach, Compositionsolubility-structure relationships in calcium (alkali) aluminosilicate hydrate (C-(N,K-)A-S-H), Dalt Trans (2015): 13530-13544. https://doi.org/10.1039/C5DT01124H

[9] R.J. Myers, Thermodynamic Modelling of CaO-Al2O3-SiO2-H2OBased Cements, The University of Sheffield, 2015.

[10] R.J. Myers, E. L'Hôpital, J.L. Provis, B. Lothenbach, Effect of temperature and aluminium on calcium (alumino)silicate hydrate chemistry under equilibrium conditions, Cem Concr Res (2015) 68: 83-93. https://doi.org/10.1016/i.cemconres.2014.10.015

[11] R.J. Myers, S.A. Bernal, J.L. Provis, A thermodynamic model for C-(N)A-S-H gel: CNASH_ss. Derivation and validation, Cem Concr Res (2014) 66: 27-47. https://doi.org/10.1016/j.cemconres.2014.07.005

[12] L. Gomez-Zamorano, M. Balonis, B. Erdemli, N. Neithalath, G. Sant, $\mathrm{C}-(\mathrm{N})-\mathrm{S}-\mathrm{H}$ and $\mathrm{N}-\mathrm{A}-\mathrm{S}-\mathrm{H}$ gels: Compositions and solubility data at $25^{\circ} \mathrm{C}$ and $50^{\circ} \mathrm{C}$, J Am Ceram Soc (2017) 100: 2700-2711. https://doi.org/10.1111/jace.14715

[13] S. Wilhelm, M. Kind, Influence of $\mathrm{pH}$, temperature and sample size on natural and enforced syneresis of precipitated silica, Polymers (Basel) (2015) 7: 2504-2521. https://doi.org/10.3390/polym7121528

[14] P. Duxson, J.L. Provis, Designing Precursors for Geopolymer Cements, J Am Ceram Soc (2008) 91: 3864-3869. https://doi.org/10.1111/j.1551-2916.2008.02787.x

[15] P. Duxson, J.L. Provis, G.C. Lukey, F. Separovic, J.S. van Deventer, 29Si NMR study of structural ordering in aluminosilicate geopolymer gels, Langmuir (2005) 21: 3028-3036. https://doi.org/10.1021/la047336x

[16] P. Duxson, J.L. Provis, G.C. Lukey, S.W. Mallicoat, W.M. Kriven, J.S.J. van Deventer, Understanding the relationship between geopolymer composition, microstructure and mechanical properties, Colloids Surfaces A Physicochem. Eng Asp (2005) 269: 47-58. https://doi.org/10.1016/j.colsurfa.2005.06.060

[17] W.K.W. Lee, J.S.J. Van Deventer, Structural reorganisation of class $F$ fly ash in alkaline silicate solutions, Colloids Surfaces A Physicochem. Eng Asp (2002) 211: 49-66. https://doi.org/10.1016/S0927-7757(02)00237-6

[18] J.L. Devidal, J. Schott, J.L. Dandurand, An experimental study of kaolinite dissolution and precipitation kinetics as a function of chemical affinity and solution composition at $150 \mathrm{C}, 40$ bars, and $\mathrm{pH}$ 2, 6.8, and 7.8, Geochim Cosmochim Acta (1997) 61: 5165-5186. https://doi.org/10.1016/S0016-7037(97)00352-9

[19] T.W. Swaddle, J. Salerno, P.A. Tregloan, Aqueous Alulminates, Silicates, and Aluminosilicates, Chem Soc Rev (1994) 23: 319-325. https://doi.org/10.1039/cs9942300319
[20] P. Duxson, G.C. Lukey, F. Separovic, J.S.J. van Deventer, Effect of Alkali Cations on Aluminum Incorporation in Geopolymeric Gels, Ind Eng Chem Res (2005) 44: 832-839. https://doi.org/10.1021/ie0494216

[21] R.K. Iler, The Chemistry of Silica, John Wiley and Sons, New York, 1979.

[22] J.L. Provis, P. Duxson, G.C. Lukey, F. Separovic, W.M. Kriven, J.S.J. Van Deventer, Modeling Speciation in Highly Concentrated Alkaline Silicate Solutions, Ind Eng Chem Res (2005) 44: 8899-8908. https://doi.org/10.1021/ie050700i

[23] A.V. McCormick, A.T. Bell, C.J. Radke, Multinuclear NMR Investigation of the Formation of Aluminosilicate Anions, J Phys Chem (1989) 93: 1741-1744. https://doi.org/10.1021/j100342a015

[24] E. L'Hôpital, B. Lothenbach, G. Le Saout, D. Kulik, K. Scrivener, Incorporation of aluminium in calcium-silicate-hydrates, Cem Concr Res (2015) 75: 91-103. https://doi.org/10.1016/j.cemconres.2015.04.007

[25] I. Garcia-Lodeiro, A. Palomo, A. Fernández-Jiménez, D.E. Macphee, Compatibility studies between N-A-S-H and C-A-S-H gels. Study in the ternary diagram Na2O-CaO-Al2O3-SiO2-H2O, Cem Concr Res (2011) 41: 923-931. https://doi.org/10.1016/i.cemconres.2011.05.006

[26] I. García-Lodeiro, A. Fernández-Jiménez, A. Palomo, D.E. Macphee, Effect of Calcium Additions on N-A-S-H Cementitious Gels, J Am Ceram Soc (2010) 1940: 1934-1940. https://doi.org/10.1111/j.1551-2916.2010.03668.x

[27] B.R.W. Pinsent, L. Pearson, F.J.W. Roughton, The kinetics of combination of carbon dioxide with hydroxide ions, Trans Farady Soc (1956) 52: 1512-1520. https://doi.org/10.1039/tf9565201512

[28] P.M. Dove, The dissolution kinetics of quartz in aqueous mixed cation solutions, Geochim Cosmochim Acta (1999) 63: 3715-3727. https://doi.org/10.1021/jp0713413

[29] M. Rowles, B. O'Connor, Chemical optimisation of the compressive strength of aluminosilicate geopolymers synthesised by sodium silicate activation of metakaolinite, J Mater Chem (2003) 13: 11611165. https://doi.org/10.1039/b212629j

[30] K.L. Aughenbaugh, T. Williamson, M.C.G. Juenger, Critical evaluation of strength prediction methods for alkali-activated fly ash, Mater Struct Constr (2014) 48. https://doi.org/10.1617/s11527-014-0496-z

[31] V.F.F. Barbosa, K.J.D. MacKenzie, C. Thaumaturgo, Synthesis and characterisation of materials based on inorganic polymers of alumina and silica: sodium polysialate polymers, Int J Inorg Mater (2000) 2: 309-317. https://doi.org/10.1016/S1466-6049(00)00041-6

[32] T. Williamson, J. Han, L. Katz, H.A. Dobbs, B.F. Chmelka, G. Sant, M.C.G. Juenger, Relationship Between Aqueous Chemistry and Composition, Structure, and Solubility of Sodium Aluminosilicate Hydrates, Prep. Submiss. (n.d.).

[33] R. Baird, L. Bridgewater, Part 3000 Metals, Standard methods for the examination of water and wastewater, 23rd ed., American Public Health Association, Washington, D.C., 2017.

[34] EPA, Determination of Metals and Trace Elements in Water and Wastes by Inductively Coupled Plasma-Atomic Emission Spectrometry, 1994.

[35] H. Xiandeng, R.S. Amais, B.T. Jones, G.L. Donati, Inductively Coupled Plasma Optical Emission Spectrometry, in: Encycl. Anal. Chem., John Wiley and Sons, (2000): 1-25.

[36] G. Sposito, The Chemistry of Soils, 2nd ed., Oxford University Press, 2008.

[37] R.A. Robinson, R.H. Stokes, Electrolyte Solutions, 2nd Editio, London, 1959.

[38] K.S. Pitzer, The Treatment of Ionic Solutions over the Entire Miscibility Range, Reports Bunsen Soc Phys Chem (1981) 85: 952959. https://doi.org/10.1002/bbpc.19810851107 